University of Nebraska - Lincoln

DigitalCommons@University of Nebraska - Lincoln

Biological Systems Engineering: Papers and

Publications

Biological Systems Engineering

2021

\title{
Differential Survival of Non-0157 Shiga Toxigenic Escherichia coli in Simulated Cattle Feedlot Runoff
}

Lisa M. Durso

USDA-ARS, Lisa.Durso@ars.usda.gov

John E. Gilley

Adjunct Professor, Biological Systems Engineering, john.gilley@ars.usda.gov

Daniel N. Miller

USDA-ARS, daniel.miller@usda.gov

Follow this and additional works at: https://digitalcommons.unl.edu/biosysengfacpub

Part of the Bioresource and Agricultural Engineering Commons, Environmental Engineering Commons, and the Other Civil and Environmental Engineering Commons

Durso, Lisa M.; Gilley, John E.; and Miller, Daniel N., "Differential Survival of Non-0157 Shiga Toxigenic Escherichia coli in Simulated Cattle Feedlot Runoff" (2021). Biological Systems Engineering: Papers and Publications. 783.

https://digitalcommons.unl.edu/biosysengfacpub/783

This Article is brought to you for free and open access by the Biological Systems Engineering at DigitalCommons@University of Nebraska - Lincoln. It has been accepted for inclusion in Biological Systems Engineering: Papers and Publications by an authorized administrator of DigitalCommons@University of Nebraska Lincoln. 


\title{
Differential Survival of Non-0157 Shiga Toxigenic Escherichia coli in Simulated Cattle Feedlot Runoff
}

\author{
Lisa M. Durso,' John E. Gilley, and Daniel N. Miller
}

\begin{abstract}
Environmental survival time is important when evaluating adverse health outcomes from foodborne pathogens. Although outbreaks associated with manure-impacted irrigation or runoff water are relatively infrequent, their broad scope, regulatory importance, and severe health outcomes highlight the need to better understand the environmental survival of manure-borne pathogens. Shiga toxigenic Escherichia coli (STEC) are excreted in feces and persist in the environment until they die or recolonize a new host. Surface waters contaminated with manure-borne STEC can infect humans through drinking and recreational water use or irrigated crops that are minimally cooked. In this study, manure-impacted water microcosms mimicking beef cattle feedlot runoff were used to assess survival of STEC strains representing seven STEC serotypes (O26, O45, O103, O111, O121, $\mathrm{O} 145$, and $\mathrm{O} 157$ ) and persistence of target $\mathrm{O}$ antigen genes. Microcosms were sampled over the course of 1 year, and the entire experiment was repeated in a second year. Culture and polymerase chain reaction (PCR)based techniques were used for detection and enumeration. Serotype-specific survival results were observed. Both STEC O26 and O45 declined slowly and remained culturable at 24 months. In contrast, STEC O121 and O145 decreased rapidly ( -0.84 and $-1.99 \log 10$ abundance per month, respectively) and were unculturable by months 4 and 5, but detectable by PCR for a mean of 4.5 and 8.3 months, respectively. STEC O103, O111, and O157 remained culturable for a mean of 11.6, 5.5, and 15 months and detectable by PCR for a mean of 12, 13.8, and 18.6 months after inoculation, respectively. Results document that some STEC serotypes have the biological potential to survive in manure-impacted waters for extended periods of time when competing microflora are eliminated. Serotype-specific differences in survival of target bacteria and persistence of target genes were observed in this sample set, with STEC O26 and O45 strains appearing the most robust in these microcosm studies.
\end{abstract}

Keywords: Shiga toxigenic E. coli, STEC O157, non-O157 STEC, survival, environment, manure

\section{Introduction}

$\mathbf{S}$ HIGA TOXIGENIC ESCHERICHIA COLI (STEC) are foodborne pathogens associated with potentially lifethreatening gastrointestinal illness. Severe complications such as hemolytic uremic syndrome or death are associated with outbreaks of this group of pathogens (Fremaux et al., 2008). STEC with the O157 serotype emerged widely as an important foodborne pathogen in the 1980s, associated primarily with beef (Kaper and O'Brien, 2014). In 1994, STEC O157 was declared an adulterant in beef in the United States, and in 2012, six additional STEC serotypes (non-O157 STEC) were added: O26, O45, O103, O111, O121, and O145 (USDA, 2011). While early U.S. STEC outbreaks were pri- marily associated with STEC O157 in cattle production systems, today, non-O157 STEC outbreak cases in the United States outnumber STEC O157 cases (CDC, 2016), and in 2018-2019, the CDC reported twice as many lettuceassociated versus beef-associated STEC outbreaks (https:// www.cdc.gov/ecoli/outbreaks.html).

Manure-borne STEC is a major contaminant of leafy greens, with transmission occurring through direct contact with wildlife or cattle feces and through runoff, dust, and insects (Berry et al., 2019a, 2019b). There is also growing concern with the transmission of STEC to produce through irrigation with STEC-contaminated water (Gelting et al., 2011; Mikhail et al., 2018; Haymaker et al., 2019), including the potential for uptake of STEC from manure-impacted 
surface and irrigation water and internalization into plant tissue (Merget et al., 2019). Specifically, animal manureimpacted irrigation water is considered under the Food Safety Modernization Act to be a potential primary source of contamination for produce (FDA, 2015), with produce-related events often resulting in multistate outbreaks (Heiman et al., 2015). Although outbreaks associated with manure-impacted irrigation water are relatively infrequent, their broad scope, regulatory importance, and severe health outcomes highlight the need to better understand the environmental survival of these important pathogens.

E. coli, including STEC, naturally cycle between the warm, nutrient-rich, lower gastrointestinal tract (GIT) of animals, which is their primary habitat, and environments external to the host, including water, soil, and air (Savageau, 1983). Individual $E$. coli cells persist in the natural environment until they either recolonize a mammalian host or they die (Savageau, 1983). Thus, environmental survival time is a critical component contributing to contamination of produce and the ability of STEC to eventually reach and infect a human host (Brouwer et al., 2019).

Increasing evidence reveals that there are important phenotypic differences in how STEC 0157 and non-O157 STEC persist in the GIT, manure, food, and soils (Free et al., 2012; Brouwer et al., 2019; Merget et al., 2020). For example, Ma et al. (2014) examined the persistence of STEC in agricultural soil microcosms and found that some non-O157 STEC serotypes survived significantly longer than STEC O157s, citing strain and soil type as drivers for the observed differences. There is a substantial body of literature examining the survival of STEC O157 under various extraintestinal conditions (Fremaux et al., 2008; Topalcengiz and Danyluk, 2019; Reynolds et al., 2020). However, data characterizing the survival potential of STEC and non-O157 STEC in runoffcontaminated irrigation water are sparse and inconsistent. The goal of the present investigation was to assess the biological potential of individual STEC strains to persist in manure-impacted water microcosms. We hypothesize that STEC will display a variety of serotype-specific survival phenotypes. If true, then extrapolating specific 0157 survival characteristics to the broader E. coli community may not be supported.

\section{Materials and Methods}

\section{Simulated runoff}

Soil was collected from the University of Nebraska Rogers Memorial Farm, which had been used in previous field runoff studies (Durso et al., 2019). The Aksarben soil from which samples were collected developed in loess under prairie vegetation and is considered a benchmark soil for the Western Corn Belt. The site had been cropped to corn the previous cropping season. Soil was collected from the surface of selected locations (top $10 \mathrm{~cm}$ ), brought into the laboratory, dried, and sieved. Beef cattle manure was collected from the U.S. Meat Animal Research Center feedlot near Clay Center, NE. An aliquot was sent to Ward Laboratories (Kearney, NE) for nutrient analysis to determine the agronomic rate for use in laboratory tests (Supplementary Table S1). Manure was added to dried soil at a rate of $25.8 \mathrm{~kg} \mathrm{P} \mathrm{ha}^{-1} \mathrm{P}$ to meet the 1year P-based application requirement for an expected corn yield of $9.4 \mathrm{Mg} \mathrm{ha}^{-1}$. Five grams of manure-amended soil was mixed into $787 \mathrm{~mL}$ of sterile distilled water in a 1-L sterile Nalgene bottle, resulting in turbidity of 600-700 nephelometric turbidity units, similar to field-collected runoff (Durso et al., 2017). To determine the ability of each STEC serotype to survive or persist and to eliminate the stochasticity and variability introduced by competition from and predation by competing microflora, the microcosms were autoclaved before inoculation. Once cooled to room temperature, bottles were inoculated and stored at $4^{\circ} \mathrm{C}$ for the duration of the experiment to maximize bacterial survival time and to represent cooler temperatures outside of the GIT. Measurements were taken by removing bottles from the cooler, thoroughly mixing the bottles by shaking for $30 \mathrm{~s}$, and taking aliquots for dilution and plating, after which the bottles were returned to storage.

\section{Bacterial strains and culture conditions}

Seven STEC serotypes were used for this study: O26, O45, O103, O111, O121, O145, and O157 (Supplementary Table S2). To facilitate enumeration, strains were tagged with nalidixic acid resistance, as described previously ( $\mathrm{Ma}$ et al., 2014). STEC cultures were grown in tryptic soy broth containing $25 \mu \mathrm{g} / \mathrm{mL}$ nalidixic acid (TSB+Nal) overnight at $37^{\circ} \mathrm{C}$. Cultures were adjusted to $\mathrm{OD}_{600}=0.300$, equivalent to a concentration of $\sim 10^{8}$ colony-forming units (CFUs) $/ \mathrm{mL}$. Each culture was serially diluted and spread-plated on $\mathrm{TSA}+\mathrm{Nal}$ in duplicate to confirm the exact concentration of the stock culture. Cultures were adjusted by concentration so that each simulated runoff container was spiked with $10^{6}$ $\mathrm{CFUs} / \mathrm{mL}$. All experiments were performed using triplicate bottles for each serotype, for a total of 21 simulated runoff bottles ( 7 serotypes, 3 replicates per serotype), evaluated over the course of 1 year. The entire experimental design was replicated for a second year for four of the seven serotypes that had displayed either robust survival (O26 and O45) or quick decline (O121 and O145). For microcosms from year 1, when cells remained culturable or DNA persisted in triplicate samples after the initial 12-month study was completed, those bottles were evaluated monthly through year 2 to obtain $3-\log 10$ reduction times.

\section{Bacterial Enumeration}

The simulated runoff in each prepared bottle was plated preinoculation and directly after being inoculated with $\sim 10^{6}$ CFUs/mL (Day 0). The overnight cultures used for inoculation were also immediately plated to determine the exact spike for each strain. Subsequent aliquots were plated, in duplicate, for enumeration in the simulated runoff on the following schedule: Day 1, Day 2, Day 5, Day 7, Day 14, Day 21, Day 28, Day 36, and Day 42 and then monthly until two consecutive plating instances produced zero colonies. Once quantification was no longer possible, aliquots were enriched for presence/absence detection.

At each sampling date, $1 \mathrm{~mL}$ of spiked simulated runoff water was diluted in $1 \mathrm{X}$ phosphate-buffered saline and then spread-plated, in duplicate, on tryptic soy agar $+25 \mu \mathrm{g} / \mathrm{mL}$ nalidixic acid at the levels required to produce countable plates with 20-200 colonies per plate. Samples were thoroughly mixed by shaking for $30 \mathrm{~s}$ before aliquots were taken for dilution and plating. Plates were incubated at $37^{\circ} \mathrm{C}$ for $24 \mathrm{~h}$ for all samples, except those inoculated with STEC 
O111. The STEC 0111 plates were incubated at $37^{\circ} \mathrm{C}$ for $48 \mathrm{~h}$ for ease of counting due to observed slower growth. Following incubation, plates were counted and 10 colonies from each bottle were selected for confirmatory polymerase chain reaction (PCR). Confirmatory PCR primers and thermocycling conditions are listed in Table 1. All isolates from countable plates were confirmed with PCR once fewer than 20 isolates grew on the $10^{-1}$ plates. For the $10^{0}$ dilution plates with 1-10 colonies, all colonies were isolated and screened. Plating for enumeration was continued until two consecutive instances with zero colonies were observed (i.e., no colonies on the $10^{\circ}$ plates).

When colonies were no longer observed after direct plating of the simulated runoff on either of the duplicate plates at the lowest dilution level, an enrichment detection method was utilized to determine if viable STEC could be enriched (culture based) or STEC genes (PCR based) could be detected. One milliliter of the spiked simulated runoff in the bottle was combined with $9 \mathrm{~mL}$ of TSB+Nal and enriched overnight at $37^{\circ} \mathrm{C}$ for $24 \mathrm{~h}$ (or $48 \mathrm{~h}$ for $\mathrm{O} 111$ for ease of counting due to slower growth), followed by plating for isolates and isolate screening using serotype-specific PCR (culture based). Additionally, the enriched sample was directly screened for serotype-specific genes (PCR based). This enrichment/PCR-based detection was performed on each sample bottle until negative PCR results were obtained for two consecutive sample dates, at which time the incubation was discontinued.

\section{Statistical analysis}

The various STEC strains were compared based upon changes in $\log 10$ abundance during the simulated runoff incubation. Strains were assessed for a postinoculation increase, differences in number of days for a 3- $\log 10$ reduction, and for month of last detection using an analysis of variance (ANOVA) (proc general linear models [GLM]) and least squares means comparison using Student $t$-tests (SAS, version 9.2; SAS Institute, Cary, NC). Linear regression was first used to calculate the rate of $\log 10$ abundance change (slope of the regression line) for each replicate using data from month 1 through month 12, followed by an ANOVA (proc GLM) and least squares means to determine differences $(p<0.05)$ between strains. Differences in survival times (using the number of months elapsed from the onset of the experiment until last detection by either culture-based or PCR-based methods) were determined using the least squares means. Since strains $\mathrm{O} 45, \mathrm{O} 26$, and $\mathrm{O} 103$ survived through the last month of the incubation, the total number of incubation months (30 or 20) was used for statistical purposes.

\section{Results}

Serotype-specific survival differences were observed as the abundance of STEC strains changed during the incubation (Fig. 1). Survival times for the seven STEC strains studied ranged from 3 to at least 30 months (Table 2). Three of the seven strains $(\mathrm{O} 26, \mathrm{O} 45$, and $\mathrm{O} 103)$ initially increased in abundance (from $\sim 10^{6}$ to $10^{7} \mathrm{CFUs} / \mathrm{mL}$ ) within the first 2 weeks after inoculation into the manure-impacted water microcosms (Fig. 2) and remained culturable at the 12-month sampling point. In contrast, STEC O111, O121, and O145 strains decreased immediately upon inoculation into the simulated runoff and culturable populations declined below enumerable levels within 6 months (Fig. 1). O157 showed no increase in abundance, but was culturable for the full 12 months of the experiment.

Table 1. Polymerase Chain Reaction Primers and Annealing Temperatures

\begin{tabular}{|c|c|c|c|c|}
\hline $\begin{array}{l}\text { STEC } \\
\text { target }\end{array}$ & Primer sequences $\left(5^{\prime}-3^{\prime}\right)$ & $\begin{array}{l}\text { Amplicon } \\
\text { size }(b p)\end{array}$ & Thermocycling conditions & Citation \\
\hline $\mathrm{O} 26$ & $\begin{array}{l}\text { AAATTAGAAGCGCGTTCATC } \\
\text { CCCAGCAAGCCAATTATGACT }\end{array}$ & 596 & $\begin{array}{l}95^{\circ} \mathrm{C} \text { for } 15 \mathrm{~min} ; 35 \text { cycles at } 94^{\circ} \mathrm{C} \text { for } \\
60 \mathrm{~s}, 56^{\circ} \mathrm{C} \text { for } 60 \mathrm{~s} \text {, and } 72^{\circ} \mathrm{C} \text { for } 60 \mathrm{~s} \text {; } \\
\text { and } 1 \text { cycle at } 72^{\circ} \mathrm{C} \text { for } 10 \mathrm{~min}\end{array}$ & $\begin{array}{l}\text { Paton and Paton } \\
\text { (1998) }\end{array}$ \\
\hline $\mathrm{O} 45$ & $\begin{array}{l}\text { GGGCTGTCCAGACAGTTCAT } \\
\text { TGTACTGCACCAATGCACCT }\end{array}$ & 890 & $\begin{array}{l}94^{\circ} \mathrm{C} \text { for } 5 \mathrm{~min} ; 35 \mathrm{cycles} \text { at } 94^{\circ} \mathrm{C} \text { for } 30 \mathrm{~s} \\
\text { and } 67^{\circ} \mathrm{C} \text { for } 80 \mathrm{~s} \text {; and } 1 \text { cycle at } 68^{\circ} \mathrm{C} \\
\text { for } 7 \mathrm{~min}\end{array}$ & $\begin{array}{l}\text { Paddock et al. } \\
\qquad(2012)\end{array}$ \\
\hline O103 & $\begin{array}{l}\text { TAAGTACGGGGGTGCTTTTT } \\
\text { AAGCTCCCGAGCACGTATAA }\end{array}$ & 716 & $\begin{array}{l}94^{\circ} \mathrm{C} \text { for } 5 \mathrm{~min} ; 35 \text { cycles at } 94^{\circ} \mathrm{C} \text { for } 30 \mathrm{~s} \\
\text { and } 67^{\circ} \mathrm{C} \text { for } 80 \mathrm{~s} \text {; and } 1 \text { cycle at } 68^{\circ} \mathrm{C} \\
\text { for } 7 \mathrm{~min}\end{array}$ & $\begin{array}{l}\text { Paddock et al. } \\
\quad(2012)\end{array}$ \\
\hline O111 & $\begin{array}{l}\text { AGAGAAATTATCAAGTTAGTTCC } \\
\text { ATAGTTATGAACATCTTGTTTAGC }\end{array}$ & 406 & $\begin{array}{l}95^{\circ} \mathrm{C} \text { for } 15 \mathrm{~min} ; 35 \text { cycles at } 94^{\circ} \mathrm{C} \text { for } \\
60 \mathrm{~s}, 53^{\circ} \mathrm{C} \text { for } 60 \mathrm{~s} \text {, and } 72^{\circ} \mathrm{C} \text { for } 60 \mathrm{~s} \\
\text { and } 1 \text { cycle at } 72^{\circ} \mathrm{C} \text { for } 10 \mathrm{~min}\end{array}$ & $\begin{array}{l}\text { Paton and Paton } \\
\text { (1998) }\end{array}$ \\
\hline O121 & $\begin{array}{l}\text { TCATTAGCGGTAGCGAAAGG } \\
\text { TTCTGCATCACCAGTCCAGA }\end{array}$ & 587 & $\begin{array}{l}94^{\circ} \mathrm{C} \text { for } 5 \mathrm{~min} ; 35 \text { cycles at } 94^{\circ} \mathrm{C} \text { for } 30 \mathrm{~s} \\
\text { and } 67^{\circ} \mathrm{C} \text { for } 80 \mathrm{~s} \text {; and } 1 \text { cycle at } 68^{\circ} \mathrm{C} \\
\text { for } 7 \mathrm{~min}\end{array}$ & $\begin{array}{l}\text { Paddock et al. } \\
\text { (2012) }\end{array}$ \\
\hline $\mathrm{O} 145$ & $\begin{array}{l}\text { TGCTCGACTTTTACCATCAAC } \\
\text { AACCAACACCATACACCTTGTCTT }\end{array}$ & 374 & $\begin{array}{l}94^{\circ} \mathrm{C} \text { for } 5 \mathrm{~min} ; 35 \mathrm{cycles} \text { at } 94^{\circ} \mathrm{C} \text { for } 30 \mathrm{~s} \\
\text { and } 67^{\circ} \mathrm{C} \text { for } 80 \mathrm{~s} \text {; and } 1 \text { cycle at } 68^{\circ} \mathrm{C} \\
\text { for } 7 \mathrm{~min}\end{array}$ & $\begin{array}{l}\text { Paddock et al. } \\
\quad \text { (2012) }\end{array}$ \\
\hline O157 & $\begin{array}{l}\text { CGGACATCCATGTGATATGG } \\
\text { TTGCCTATGTACAGCTAATCC }\end{array}$ & 259 & $\begin{array}{l}95^{\circ} \mathrm{C} \text { for } 15 \mathrm{~min} ; 35 \text { cycles at } 94^{\circ} \mathrm{C} \text { for } \\
60 \mathrm{~s}, 53^{\circ} \mathrm{C} \text { for } 60 \mathrm{~s} \text {, and } 72^{\circ} \mathrm{C} \text { for } 60 \mathrm{~s} \text {; } \\
\text { and } 1 \text { cycle at } 72^{\circ} \mathrm{C} \text { for } 10 \mathrm{~min}\end{array}$ & $\begin{array}{l}\text { Paton and Paton } \\
\text { (1998) }\end{array}$ \\
\hline
\end{tabular}

According to BLAST-NCBI, the polymerase chain reaction primers align with each target serotype.

STEC, Shiga toxigenic Escherichia coli. 


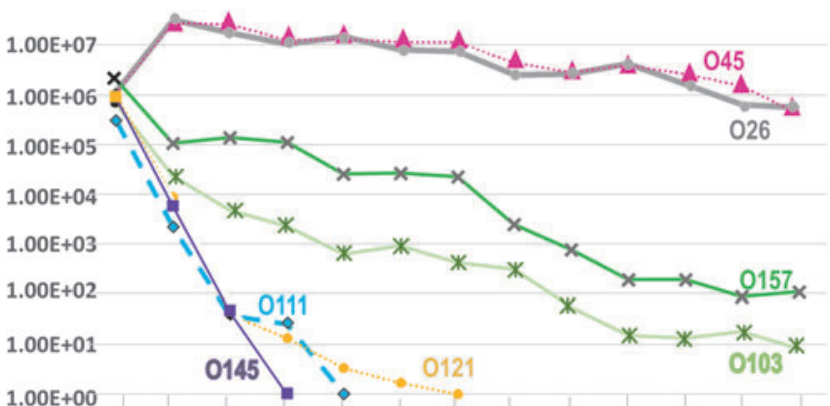

M0 M1 M2 M3 M4 M5 M6 M7 M8 M9 M10 M11 M12 Time in Months

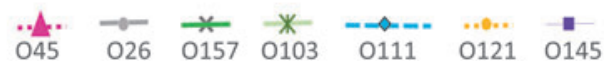

FIG. 1. Enumeration of culturable cells over time. Plating for enumeration of multiple STEC serotypes was continued until there were 2 consecutive instances with 0 colonies on the 100 plates. Microcosms consisted of $5 \mathrm{~g}$ of manureamended soil added to $787 \mathrm{~mL}$ of sterile distilled water, resulting in turbidity of 600-700 nephelometric turbidity units, similar to runoff collected from the field. Nomenclature: $(\mathrm{M})$ denotes month; STEC strains are listed by somatic (O) antigen. STEC, Shiga toxigenic Escherichia coli.

Comparing the 3-log 10 reduction times showed that STEC strains varied considerably, ranging from 37 to $576 \mathrm{~d}$, with statistically significant differences (Table 2). One group (O26 and $\mathrm{O} 45)$ exhibited strong resilience $(>500 \mathrm{~d}$ for a $3-\log 10$ reduction) to conditions in the simulated runoff, while another group (O103, O111, O121, and O145) was much more sensitive to conditions ( $<50 \mathrm{~d}$ for a $3-\log 10$ reduction). STEC O157 exhibited a more moderate response and displayed a $3-\log 10$ reduction in $168 \mathrm{~d}$.

Comparing month of last detection as a survival metric between STEC strains could provide insights into strain variation; however, it will likely be strongly influenced by the initial STEC abundance in the simulated runoff, therefore a special effort was made to have the initial STEC abundance levels as equivalent as possible. Enrichment methods were used to assess whether any viable STEC strains (or their genes) that remained in the simulated runoff showed clear STEC strain differences (Table 2). Month of last culturebased and PCR-based detections ranged from 4 to $30+$ months. Comparing detection methods, STEC in microcosm samples remained detectable from 2 to 12 months longer using the PCR-based detection of serotype-specific genes compared with the culture-based approach. However, some STEC strains (O45, O121, and O145) demonstrated no difference between culture-based and PCR-based detection. The correlation between culture- and PCR-based methods was quite strong $(r=0.891)$.

The rates of $\log 10$ abundance change per month during the incubation (month 1 to month 12) ranged from -0.150 to $-1.995 \log 10$ (Table 2). There were significant differences $(p<0.05)$ between the strains, with the longest surviving strains $(\mathrm{O} 26, \mathrm{O} 45, \mathrm{O} 103$, and $\mathrm{O} 157)$ having the lowest rates of decline and shortest surviving strains (O111, O121, and O145) having the highest rates of decline. Correlation between the rate of change in abundance and interval required for a $3-\log 10$ reduction was moderate $(r=0.535)$. This aspect of survival is expected to be insensitive to initial STEC abundance and may be a better means for comparison among independent studies.

Due to the striking difference between the survival attributes of STEC O26 and O45 strains compared with the more sensitive $\mathrm{O} 121$ and $\mathrm{O} 145$ strains, the experiment was repeated for these isolates in a second year of the study. Similar results were observed (Fig. 3). First, both $\mathrm{O} 26$ and $\mathrm{O} 45$ demonstrated an initial increase in abundance during the first month of incubation. While STEC O26 and O45 were culturable through month $12, \mathrm{O} 121$ and $\mathrm{O} 145$ were no longer detectable by month 2 . Enrichment, followed by culturebased and PCR-based detection, was also consistent with the prior study. Continued examination of the year 1 microcosms resulted in continued culture of STEC O26, O45, and $\mathrm{O} 103$ and detection of $\mathrm{O} 157$ at 18 months. Finally, although the

Table 2. Summary of Log Abundance (Per mL) and Comparisons of Survival/Persistence of Shiga Toxigenic EsCherichia COLI SERotypes in Simulated FeEdlot RunOFF

\begin{tabular}{|c|c|c|c|c|c|c|c|c|}
\hline \multirow[b]{2}{*}{ Strain } & \multicolumn{4}{|c|}{ STEC abundance } & \multirow{2}{*}{$\begin{array}{l}3-\log \\
\text { reduction, days }\end{array}$} & \multicolumn{2}{|c|}{ Month of last detection ${ }^{\mathrm{a}}$} & \multirow{2}{*}{$\begin{array}{l}\text { Rate of change } \\
\text { log/month }^{\mathrm{b}}\end{array}$} \\
\hline & Initial & Peak & $\mathrm{p}$ & Peak day & & Culture based & PCR based & \\
\hline $\mathrm{O} 26$ & 6.076 & 7.663 & $<0.001$ & 7 & $517 \mathrm{~A}$ & $26 \mathrm{~B}$ & $30+A$ & $-0.150 \mathrm{~A}$ \\
\hline $\mathrm{O} 45$ & 6.027 & 7.502 & $<0.001$ & 14 & $576 \mathrm{~A}$ & $30+A$ & $30+A$ & $-0.158 \mathrm{~A}$ \\
\hline O103 & 5.834 & 6.810 & 0.003 & 2 & $40 \mathrm{C}$ & $18 \mathrm{C}$ & $20+B$ & $-0.265 \mathrm{~A}$ \\
\hline O111 & 5.482 & 5.524 & 0.792 & 2 & $37 \mathrm{C}$ & $5 \mathrm{D}$ & $19 \mathrm{C}$ & $-0.919 \mathrm{~B}$ \\
\hline $\mathrm{O} 121$ & 6.024 & 6.232 & 0.186 & 1 & $39 \mathrm{C}$ & $4 \mathrm{D}$ & $4 \mathrm{C}$ & $-0.843 \mathrm{~B}$ \\
\hline $\mathrm{O} 145$ & 5.951 & 5.951 & 1.000 & 0 & $40 \mathrm{C}$ & $5 \mathrm{D}$ & $5 \mathrm{C}$ & $-1.995 \mathrm{C}$ \\
\hline $\mathrm{O} 157$ & 6.339 & 6.339 & 1.000 & 0 & $168 \mathrm{~B}$ & $18 \mathrm{C}$ & $20 \mathrm{~B}$ & $-0.319 \mathrm{~A}$ \\
\hline LS Mean SE & & & & & 26 & 1 & 1 & 0.148 \\
\hline
\end{tabular}

${ }^{\mathrm{a}}$ For determining the month of last detection, $1 \mathrm{~mL}$ of the simulated runoff was enriched in $9 \mathrm{~mL}$ of TSB + nalidixic acid, followed by plating. Culture-based determination examined colonies for serotype-specific PCR confirmation on the plate after enrichment, while PCRbased determination examined the enrichment broth directly for serotype-specific genes. For statistical purposes, strains present at the end of the experiment were assigned either month 30 or 20 as the month of last detection, possibly underestimating their actual survival. Strains sharing a common postscript do not differ $(p<0.05)$ in the month of last culture, 3-log reduction, or PCR-based detection.

${ }^{\mathrm{b}}$ Rate of log abundance change per month calculated from month 1 to 12 . Strains sharing a common postscript do not differ $(p<0.05)$ in their rates of change in abundance.

$\mathrm{PCR}$, polymerase chain reaction. 


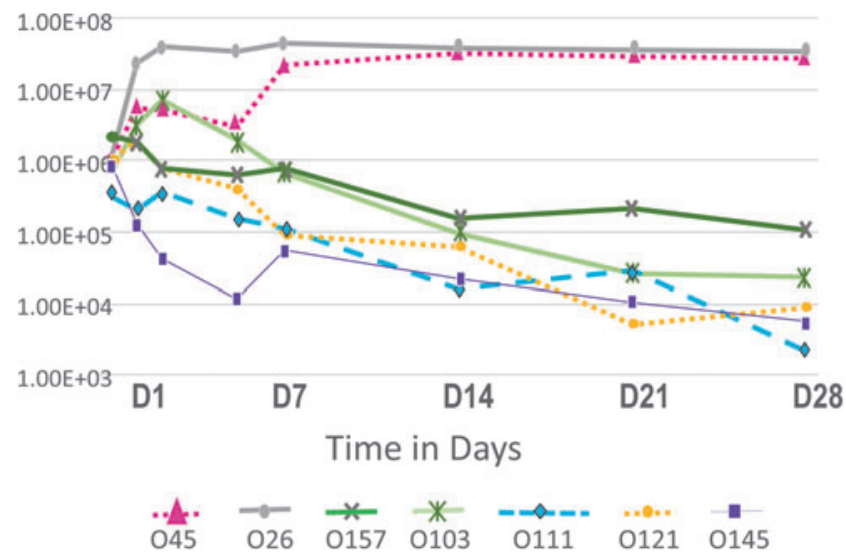

FIG. 2. Short-term enumeration of culturable cells over time (first 28 d). STEC cells were plated on Day 1, Day 2, Day 5, Day 7, Day 14, Day 21, and Day 28. Three strains (045, O26, and O103) initially grew upon addition to microcosms. Nomenclature: (D) denotes day; STEC strains are listed by somatic (O) antigen. STEC, Shiga toxigenic Escherichia coli.

rates of $\log 10$ abundance change for STEC O26 and $\mathrm{O} 45$ were lower in the second trial $(-0.092$ and -0.046$)$ compared with the first trial, the rates were not statistically different $(p>0.05)$ from the first trial.

\section{Discussion}

Environmental survival of pathogenic STEC is an important consideration when estimating the likelihood of adverse outcomes from contact with contaminated water or soil. It is also useful to inform decisions regarding remediation and control measures following contamination with manureborne STEC. In these experiments, STEC growth by some strains was observed when added to feedlot runoff microcosms. This initial increase in CFU numbers is consistent with generic $E$. coli growth patterns observed in field studies of land-applied manure slurries (Meyers et al., 2020) and is supported by evidence that some strains of $E$. coli survive for extended periods of time outside of the GIT or even natu-

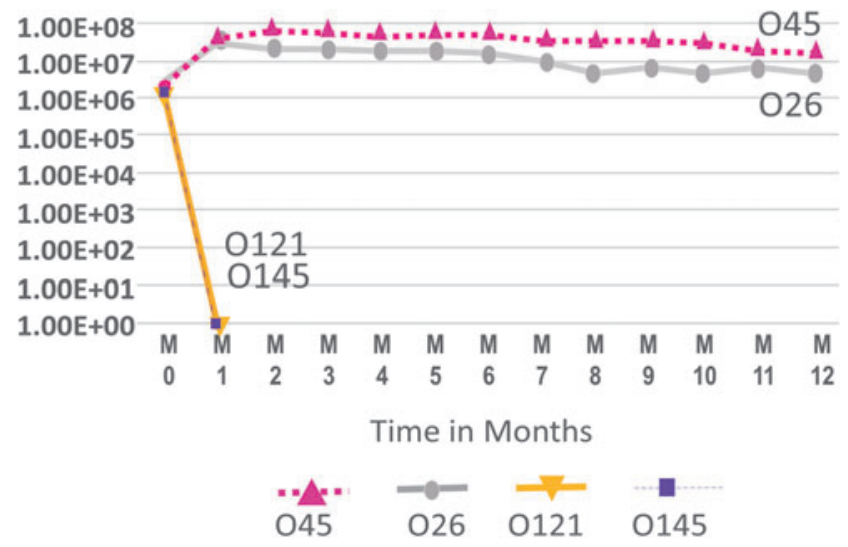

FIG. 3. Replication of the study for selected STEC strains: to confirm initial results, the full microcosm experiment was run a second time (year 2) for selected strains. Nomenclature: (M) denotes month; STEC strains are listed by somatic (O) antigen. STEC, Shiga toxigenic Escherichia coli. ralize in the extraintestinal environment (Jang et al., 2017). Evolution experiments performed by Clarke et al. (2020) with generic $E$. coli demonstrate clear genotype x environment effects for $E$. coli and note strain-level differences in the response of $E$. coli to a variety of environmental variables. In the current study of STEC survival potential, focusing on the top 6 non-O157 STEC strains under strictly restricted nutrient concentrations, we noted a consistent response between the three replicates for each strain/serotype, but heterogeneity in the responses between strains.

A growing body of evidence from this and other studies (Free et al., 2012; Ma et al., 2014; Jang et al., 2017) demonstrates a broad range of phenotypes among STEC strains involving extraintestinal survival, with some serotypes appearing to be inherently more robust. Microcosm results from this investigation using strains from seven $\mathrm{O} 157$ and nonO157 serotypes showed that some STEC strains have the biological potential to survive and remain culturable in manure-impacted waters for as long as 18 months. There also appear to be nonrandom serotype-specific differences in survival of target bacteria and persistence of target genes in the set of samples examined in this investigation.

The experimental design of this study does not allow for broad serotype-specific conclusions to be drawn; however, data presented here are consistent with other reports of serotype-specific differences in STEC prevalence and survival outside of the gut. For example, as it relates to environmental survival, Stromberg et al. (2018) reported that the O26 serotype is the most prevalent non-O157 STEC on beef cattle hides, and Dixon (2020) found O45 to be the most prevalent non-O157 STEC in cattle feces. Ma et al. (2014) found STEC O103 persisting longer than STEC O157 in soil, and Bezanson et al. (2019) determined strain-specific differences in persistence on plants, with STEC O103 persisting longer and surviving better than other strains. In this study, the STEC O26 and O45 strains remained culturable above the $10^{5} \mathrm{CFUs} / \mathrm{mL}$ range for the duration of the original 12-month study and remained culturable through months 25 and 30 , respectively. The STEC O157 strain remained culturable through month 17. However, STEC O111, O121, and O145 declined rapidly following inoculation into simulated cattle feedlot runoff. Unexpectedly, the STEC O111 microcosms remained positive by PCR $r f b O 111$ months after bacteria could no longer be recovered. It is possible that the DNA was protected in living, but not culturable, cells or that interactions with soil stabilized DNA from dead or lysed cells (Nagler et al., 2018). Together, these data highlight that the biological potential of non-O157 in the environment might be most accurately modeled using serotype-specific data. However, in all instances, studies using many more strains of each serotype are needed before any serotype-specific approaches can be recommended.

Under field conditions, the survival potential of STEC is tempered by many factors not accounted for in the current set of microcosm experiments. The composite of macroecological elements such as temperature, precipitation, and sunlight; microecological elements such as $\mathrm{pH}$; and other localized physical, chemical, and biological parameters results in a complex collection of selection pressures that impact the survival of individual bacterial taxa. Competition with the native manure, soil, and waterborne microbial communities and predation by micro- and mesofauna can 
influence the persistence of STEC in the environment in a site-dependent manner (Ma et al., 2014; Moynihan et al., 2015). The long survival times observed in this study would not be expected under field conditions where the target organisms are subjected to fluctuating temperatures and must compete with the native microbial flora. Knowing the survival potential of target pathogens in the absence of a myriad of other selective forces provides a baseline for understanding more complex interactions in the natural environment.

\section{Conclusions}

Food animal manure is an important source of STEC, and runoff from grazing areas, confined food animal operations, or land application sites can introduce STEC into surface waters. In the current study, STEC O26 and O45 strains appeared to be the most environmentally robust, remaining culturable for more than a year when found in simulated runoff. Results presented here support conclusions from other studies conducted in soil and food matrices, which demonstrated strain and serotype-specific differences in survival of STEC serotypes in the E. coli extraintestinal habitat. Serotype-specific differences in STEC environmental persistence should be considered when evaluating potential exposure from manure-impacted runoff.

\section{Author Contributions}

L.M.D. was involved in conceptualization, project management, methodology, analysis, writing — original draft preparation, and writing-reviewing and editing. J.E.G. was involved in methodology, analysis, and writing-reviewing and editing. D.N.M. was involved in methodology, data curation, statistical analysis, and writing-reviewing and editing.

\section{Acknowledgments}

The authors extend their thanks to their outstanding technical support staff, who were instrumental in collection of the data reported in this article; and ARS colleagues at the U.S. Meat Animal Research Center for sharing isolates and for helpful advice on PCR design.

\section{Disclaimer}

Mention of trade names or commercial products in this article is solely for the purpose of providing specific information and does not imply recommendation or endorsement by the U.S. Department of Agriculture. USDA is an equal opportunity provider and employer.

\section{Disclosure Statement}

No competing financial interests exist.

\section{Funding Information}

This work was supported by the USDA-Agricultural Research Service National Program 212: Soil and Air funding to project 3042-12630-003-00D.

\section{Supplementary Material}

Supplementary Table S1

Supplementary Table S2

\section{References}

Berry ED, Wells JE, Durso LM, Friesen KM, Bono JL, Suslow TV. Occurrence of Escherichia coli $\mathrm{O} 157: \mathrm{H} 7$ in cattle pest flies captured in leafy greens plots grown near a beef cattle feedlot. J Food Prot 2019a;82:1300-1307.

Berry ED, Wells JE, Durso LM, Friesen KM, Bono JL, Suslow TV. Occurrence of Escherichia coli O157:H7 in pest flies captured in leafy greens plots grown near a beef cattle feedlot. J Food Prot 2019b;82:1300- 1307.

Bezanson G, Mader D, Fillmore S, Bach S, Delaquis P. Reaction of surrogate Escherichia coli serotype O157:H7 and non-O157 strains to nutrient starvation: Variation in phenotype and transcription of stress response genes and behavior on lettuce plants in the field. J Food Prot 2019;82:1988-2000.

Brouwer AF, Eisenberg MC, Love NG, Eisenberg JNS. Phenotypic variations in persistence and infectivity between and within environmentally transmitted pathogen populations impact population $=$ level epidemic dynamics. BMC Infect Dis 2019; 19:449.

[CDC] Centers for Disease Control and Prevention. National Enteric Disease Surveillance: Shiga toxin-producing Escherichia coli (STEC) Annual Report, 2016. 2016. Available at: https://www.cdc.gov/ecoli/surv2016/index.html accessed April 19, 2021.

Clarke L, Pelin A, Phan M, Wong A. The effect of environmental heterogeneity on the fitness of antibiotic resistance mutations in Escherichia coli. Evol Ecol 2020;34:379-390.

Dixon A, Cernicchiaro N, Amachawadi RG, Shi X, Cull CA, Renter DG. Longitudinal characterization of prevalence and concentration of Shiga toxin-producing Escherichia coli serogroups in feces of individual feedlot cattle. Foodborne Path Dis 2020;17:631-639.

Durso LM, Gilley JE, Marx DB, Thayer CA, Woodbury BL. Microbial transport as affected by residue cover and manure application rate. Am Soc Agric Biol Eng 2019;62:263-270.

Durso LM, Miller DN, Snow DD, Santin M, Henry CG, Woodbury BL. Evaluation of fecal indicators and pathogens in a beef feedlot vegetative treatment system. J Environ Qual 2017;46:169-176.

Free AL, Duoss HA, Bergeron LV, Shields-Menard SA, Ward E, Callaway TR, Carroll JA, Schmidt TB, Donaldson JR. Survival of O157:H7 and non-0157 serogroups of Escherichia coli in bovine rumen fluid and bile salts. Foodborne Pathog Dis 2012;9:1010-1014.

[FDA] Food and Drug Administration. Standards for the growing, harvesting, packing, and holding of produce for human consumption. 80 FR 74353, 2015, pp. 74353-74568. Document number 2015-28159. Available at: https://www.federalregister .gov/documents/2015/11/27/2015-28159/standards-for-thegrowing-harvesting-packing-and-holding-of-produce-forhuman-consumption

Fremaux B, Prigent-Combaret C, Rozand CV. Long-term survival of Shiga toxin-producing Escherichia coli in cattle effluents and environment: An updated review. Vet Microbiol 2008;132:1-18.

Gelting RJ, Baloch MA, Bermudez MAZ, Selman C. Irrigation water issues potentially related to the 2006 multistate $E$. coli O157:H7 outbreak associated with spinach. Agric Water Manag 2011;98:1395-1402.

Haymaker J, Sharma M, Parveen S, Hashem F, May EB, Handy ET, White C, East C, Bradshaw R, Micallef SA, Callahan MT, Allard S, Anderson B, Craighead S, Gartley S, Vanore A, Kniel KE, Solamin S, Bui A, Murray R, Craddock HA, Kulikarni P, Foust D, Duncan R, Taabodi M, Sapkota AR. Prevalence of 
Shiga-toxigenic and atypical enteropathogenic Escherichia coli in untreated surface water and reclaimed water in the MidAtlantic U.S. Environ Res 2019;172:630-636.

Heiman KE, Mody RK, Johnson SD, Griffin PM, Gould LH. Escherichia coli O157 Outbreaks in the United States, 20032012. Emerg Infect Dis 2015;21:1293-1301.

Jang J, Hur HG, Sadowsky MJ, Byappanahalli MN, Yan T, Ishii S. Environmental Escherichia coli: ecology and public health implications-A review. J Appl Microbiol 2017;123:570 581.

Kaper JB, O'Brien AD. Overview and historical perspectives. Microbiol Spectr 2014;2:10.1128/microbiolspec.ehec-00282014.

Ma J, Ibekwe AM, Crowley DE, Yang CH. Persistence of Escherichia coli $\mathrm{O} 157$ and non-O157 strains in agricultural soils. Sci Total Environ 2014;490:822-829.

Merget B, Dobrindt U, Forbs KJ, Strachan NJC, Brennan F, Holden NJ. Variability in growth responses of non-O157 EHEC isolates in leafy vegetables, sprouted seeds and soil extracts occurs at the isolate level. FEMS Microbiol Lett 2020;367:fnaa030.

Merget B, Forbes KJ, Brennan F, McAteer S, Shepherd T, Strachan NJC, Holden NJ. Influence of plant species, tissue type, and temperature on the capacity of shiga-toxigenic Escherichia coli to colonize, grow, and be internalized by plants. Appl Environ Microbiol 2019;85:e00123-19.

Meyers MA, Durso LM, Gilley JE, Waldrip H, Castleberry B, Millmier-Schmidt A. Selected soil antibiotic resistance gene profile changes following manure application and rainfall. J Environ Qual 2020;49:754-761.

Mikhail AFW, Jenkins C, Dallman TJ, Inns T, Douglas A, Martin AIC, Fox A, Cleary P, Nelson R, Hawker J. An outbreak of Shiga toxin-producing Escherichia coli O157:H7 associated with contaminated salad leaves: epidemiological, genomic and food trace back investigations. Epidemiol Infect 2018;146:187-196.

Moynihan EL, Richards KG, Brennan FP, Tyrrel SF, Ritz K. Enteropathogen survival in soil from different land-uses is predominantly regulated by microbial community composition. Appl Soil Ecol 2015:89:76-84.
Nagler M, Insam H, Pietramellara G, Axher-Jenull J. Extracellular DNA in natural environnements: features, relevance and applications. Appl Microbiol Biotechnol 2018;102:63436356.

Paddock Z, Shi X, Bai J, Nagaraja TG. Applicability of a multiplex PCR to detect O26, O45, O103, O111, O121, O145, and $\mathrm{O} 157$ serogroups of Escherichia coli in cattle feces. Vet Microbiol 2012;156:381-388.

Paton AW, Paton JC. Detection and characterization of Shiga toxigenic Escherichia coli by using multiplex PCR assays for stx1, stx2, eaeA, enterohemorrhagic E. coli hlyA, rfbO111, and rfb0157. J Clin Microbiol 1998;36:598-602.

Reynolds C, Checkley S, Chui L, Otto S, Neumann NF. Evaluating the risks associated with Shiga-toxin-producing Escherichia coli (STEC) in private well waters in Canada. Can J Microbiol 2020;66:337-350.

Savageau MA. Escherichia coli habitats, cell types, and molecular mechanisms of gene control. Am Nat 1983;122:732744.

Stromberg ZR, Redweik GAJ, Mellata M. Detection, prevalence, and pathogenicity of non-O157 Shiga toxin-producing escherichia coli from cattle hides and carcasses. Foodborne Pathog Dis 2018;15:119-131.

Topalcengiz Z, Danyluk MD. Fate of generic and Shiga toxinproducing Escherichia coli (STEC) in Central Florida surface waters and evaluation of EPA Worst Case water as standard medium. Food Res Int 2019;120:322-329.

USDA. United States Department of Agriculture Shiga toxinproducing Escherichia coli in certain raw beef products. Fed Regist 2011;76:58157-58165 [Docket No. FSIS-2010-0023].

Address correspondence to:

Lisa M. Durso, PhD

USDA, ARS

Room 251 Filley Hall UNL-East Campus

Lincoln, NE 68583

USA

E-mail: lisa.durso@ars.usda.gov 